\title{
A Study on Federal Healthy Start in the USA and its Implications to Korea
}

\author{
Bo Ki Pyon ${ }^{1}$ \\ ${ }^{l}$ Professor, Department of Social Welfare, Mokwon University, Republic of Korea, bkpyon@daum.net
}

\begin{abstract}
This study aims to investigate the Federal Healthy Start program in the USA and its implications on the local welfare service system of Korea. To achive this goal, several domestic and foreign research papers, books and surveys published by private and public institutions were reviewed. According to the investigation, the program has the following features. First, it provides an integrative service in the organic relation based on the operation system by constructing the operation system among suppliers of diverse public and private services in the community. Second, experts, semi-experts, and general volunteers in the community synthetically cooperate to deliver service through outreach, home visiting, case management, etc. Third, the active participation of local inhabitants is ensured and financially supported by the federal and local government. Based on the results of this study, the implications for the local welfare service system in Korea were presented as follows. First, the roles of the diverse public and private welfare service suppliers in the community is to reorganize and enhance the connection and adjustment among institutions. Second, it is required to secure the provision of proper service which meets local inhabitants' property and desire by utilizing manpower providing diverse human service in the community. Third, it is necessary to promote the enhancement of individual and local competence by making a system where the local inhabitants can participate in the planning service. Fourth, the administrative and financial support should be provided to expand human and material infrastructure for local service through cooperative relation between the central and local government.
\end{abstract}

Keywords: Federal Healthy Start, Local Inhabitants' Participation, Community Networking, Home Visiting

\section{Introduction}

In 1991, the Health Resources and Services Administration (HRSA) under the management of the Department of Health and Human Service (HHS) introduced the Federal Healthy Start program to supply maternity protection and children's health protection services to needy women and children in urban and rural regions where the rate of infant and child mortality was 1.5 to 2 times the national average. About 30 years after the implementation of the program nationwide, it was able to provide diverse services such as medical and health protection service to local inhabitants who are relatively marginalized for race, gender, socio-economic status, and residential area[1].

The result of the Healthy Start program is not only to properly meet the necessity of the local inhabitants, but also to ensure the principle of accessibility and comprehensiveness, integration, and equality of service by delivering integrative service to them through connection between local medical institution and families in relation to preventive service in comprehensive character as well as chronic disease[2].

Furthermore, the largest feature of the Federal Healthy Start is to construct a cooperative system

Received: September 18, 2020; 1st Review Result: November 08, 2020; 2nd Review Result: December 23,2020 Accepted: January 25, 2021 
among social service institutions by putting local inhabitants' participation, the utilization of local human and material resources at the center in supply service. This may cause the expansion of social capital with voluntary cooperation of private sector. Also, a social safety net is built by emotionally and psychologically supporting those who are hardly supported individually or socially as well as promoting correlation with other inhabitants. Moreover, this contributes to the enhancement of communal inhabitants' competence, thereby making the improvement of individual and community resilience expectable[3].

The basic principle of Federal Healthy Start can be summarized as provision of innovative service, construction of cooperative system with community, enhancement of service receiver's sense of responsibility, alliance with diverse local institutions, enhancement of effect and accessibility of service, and emphasis of education for local inhabitants. On the other hand, in Korea, there is a lack of cooperative relations between the private and public sectors and between the central and local governments. In addition, the social welfare delivery system in Korea is currently providing inefficient, ineffective and discrete services. Focusing on these problems, this study tries to contribute to the development of a model that can be applied appropriately to the situation in Korea by illuminating the content and characteristics of Federal Healthy Start and the relationship between central, state and local goverments in the USA.

\section{Contents}

\subsection{Components of Federal Healthy Start[4]}

The Federal Healthy Start is composed of four core factors as part of its model of care. Healthy Start was originally designed to eliminate the structural disability, which negatively affects health and welfare of mothers and children. The background of such design is based on the premise that the intervention through the program schould be basically accompanied by reformation of unemployment, poverty, community violence, domestic violence, and medical insurance system because the ultimate goal cannot be attained by only constructing cooperative system among local service providers and implementing the Federal Healthy Start program.

\subsubsection{Community Consortium}

Federal Healthy Start program is mandated to organize a community consortium that is consist of service clients, local community inhabitants and suppliers who serve as a Advisory Board to the Federal Healthy Start staffing system. This consortium intends not only to facilitate the assessment of the Federal Healthy Start, advocacy of problem, and communication among subjects of organization with advice on local inhabitants' desire of health, but also to contribute to social and economic improvement through its services. Further, consortium members take part in helping to economically support the Healthy Start program to ensure the continuity of the program, take part in the execution of community Federal health systems action plan, and plan to establish relationships with State Title V agency.

\subsubsection{Local Health Systems Action Plan}

The Local Health Systems Action Plan (LHSAP) is established in the supporting stage which vies to be chosen for Federal Healthy Start. Each entity, which supports the program, should present a five-year practice plan to mitigate or improve factors that negatively affect mothers or children.

Then, the Federal Healthy Start should necessarily present standard which can assess and evaluate the structural and environmental disorder factors that affect the reduction of local infant mortality rate and birth of low-weight infant at delivery. Based on this, a time-bound and measurable goal and task should 
be set.

The examples of a practice plan includes the amplification plan of nursing manpower, business plan of constructing delivery center, cooperation with local government to maintain and expand the Federal Healthy Start, and a vocational training to expand employment opportunity for the Federal Healthy Start clients in the local medical institutions.

\subsubsection{Construction of Cooperative Relation with the Department in Charge of Health in the State Start Agendas}

The Human Resources and Services Administration Maternal and Child Health Bureau (HRSA/MCHB) entrusts that Federal Healthy Start build a cooperative relationship with state Health Department and tie up Federal Healthy Start agendas with the State Title V.

According to this mandate, the Federal Healthy Start receives the support of the federal subsidy program for local aid institution establishment, development of medical and health manpower in charge of the improvement of fertility, and care service before and after delivery including maternity mental health through close relation with the government.

Other Healthy Start programs work with State Medicaid agency to pay for home visiting, care management and health education, coordinating primary care services in hospital circumstances.

\subsubsection{Establishment of Maintenance Plan of the Federal Healthy Start}

Federal Healthy Start should develop five year maintenance plans to prepare the programs to constantly provide services in the local community and to draw specific practice programs after HRSA funding terminated. For instance, the comprehensive plan was established to maintain the Federal Healthy Start components funded by the state Medicare with a business profit plan and gain economic support from the federal government, state government, or private institutions.

Some programs have developed local income generating businesses where the profits are used for meeting Healthy Start program maintenance necessity. Other programs have developed social movements through public campaigns to convince government and private institutions.

These components explain why Healthy Start is key element for home visiting. For instance, cooperation with Title V and the LHSAP enables to link Federal Healthy Start to larger communitybased health plan and to support local Health Start to coordinate home visiting for perinatal health, immunizations, and chronic disease management.

\section{The Service Practice Activity of Federal Healthy Start}

As a delivery networking system based in the local community, Federal Healthy Start is able to absorb various practice models within its service structure. These are five practice core services, allowing Federal Healthy Start to successfully provide the services.

\subsection{Outreach and Recruitment of Clients}

Federal Healthy Start is for women exposed to the risk of pregnancy and their delivery and children in their homes. The outreach program is usually composed of general servers, semi-experts, and experts in charge of finding clients and encouraging participation. To this end, a social marketing technique is used to publicize service and diverse access routes are developed[5]. The main clients of the program are primipara, women in trouble in the past pregnancy, minor women, drug abuser, ex-convict, immigrants, and people with domestic problems. 


\subsection{Home Visiting and Case Management}

Home visiting and case management are significant service delivery means of the the Federal Healthy Start. Each local home visiting program has a detailed intake and screening procedure that guarantees participants who meet program criteria are registered in the program. Detailed intake is implemented so that clients may be properly supported later even when they do not want service, or they are disqualified for getting the service[6].

All programs have assessment produre that identifies clients assets and deficits. All clients may select a specialized service, which can properly meet their desire. They can also intervene with setting a goal, which can measure the effect to the program. Healthy Start programs combine case conferencing, quality assurance, and supervision to ensure that services goals are achived. The home visiting team has continuous job skill improvement training, examination, and evaluation.

There are various home visiting and case management methods to attain the objectives. Some home visiting services use Nurse Family Partnership or Healthy Families America. While other programs their own models using a mixed supplier model. Home visiting/case management services are client-centered, with direction by the home visitor, and constant evaluation of attainment of objectives. In addition. use of both evidence-based and promising practice models make the programs flexible to meet to the peculiar needs of clients.

\subsection{Health Education for Parents and Other Services}

Federal Healthy Start implements health education in many areas so that pregnant women or mothers may lead normal life while bearing and raising children. The service provider reviews personal and program data from the intake and assessment phase to find general health care and individual education needed. All service providers receive extensive training about the curriculum before providing service.

All clients are intensively trained on the contents, which include nursing, nutrition between pregnancies, pre-delivery care, prevention of disease and early detection, AIDS treatment, prevention and management of stress, formation of relation among family members, drug abuse and smoking, formation of affection with children, and management of chronic disease.

\subsection{Depression Test and Request}

Federal Healthy Start programs execute depression test and refer positively screened clients for treatment. The service providers are professionally trained on how to use the tool of depression test and interpretation of test result. The Depression test is generally done three times. Once clients are diagnosed to be in depressed state, they are referred to experts for professional treatment like personal counseling therapies and medication care.

\subsection{Interconceptional Care}

Federal Healty Start takes reponsibility for sustainability of care services through two years post delivery for each participant. In accordance with the interconceptional care protocol, participant develop a reproductive life plan with service provider. During the planning period, participant and service provider develop specific goals for the childcare, mental health test and family relationships. 
[Fig. 1] Logic Model: Federal Healthy Start Program[7]

GOAL: Improvement of maternal health and reduction of disparities in perinatal birth in USA through evidence-based practices, community cooperation, organizational execution monitoring, and quality control.

\section{SHORT-TERM OUTCOMES (UP TO 2 YRS)}

Participant

- Receipt of various services considered significant to participant

Increment of

o health insurance registration

o use of early and sustainable intervention

o use of primary health care service

o use of social and personal services

o promotion of healthy behaviors

o connection to Patient Centered Medical Home

o linkage to fathers

o parenting, meeting, and self-sufficiency knowledge and skills

o improvement of mental health

Program/Organizational System

-Increment of

o knowledge of practices and Mean Corpuscular Hemoglobin care

o rate of families that accept services and excute a referral

o participation of women who are in need

o quality of supplied services

o continuous participation in medical and social services

o Healthy Start program staff knowledge, skills, and cultural sensibility and linguistic ability

Community/System (Level 2 and 3 grantees)

- Enhanced responsiveness of networking coordination care for addressing community needs

\section{ACTIVITIES}

Implement Evidence-based Practices to Promote Women's Health, Quality Services, and Family Resilience

- Recruitment at-risk recipients for Healthy Start programs to attain participation targets

- Conduction of general evalution at intake and at predetermined stages to check participant needs and risks

- Registration of clients in health services coverage

- Development of reproductive life plan

- Guarantee provision of

o preventive services (e.g., smoking)

o case management and follow- up services for two years after birth

- Referral clients to

o primary health care programs (e.g., Patient Centered Medical Home and home visiting) and behavioral health care

o social services to relieve addiction stress

- Promote male engagement (e.g., parenting, services for men) and sound relations

Launch Collective Impact effort

n Complete Memorandum of Understanding with local community partners for Community Action Network

- Connection to national Mean Corpuscular Hemoglobin bodies (e.g., Fetel and Infant Mortality Review)

- Creation of action strategies for coordination and coopration

Coordination of local community services and database systems 
- Select grantees take part in Collaborative Improvement \& Innovation Network

\section{INPUTS}

Program Participants

- Personl factors (e.g., needs, strong and weak factors,age, gender,education,race and socioeconomic status)

- Social network (e.g., partners, children,neighbors)

Program/Organizational System

- Health Resources and Services Administration Healthy Start group

- Financed 101 Healthy Start recipients

- Provider and service networks

- National Healthy Start capability establishing support provider

- Mean Corpuscular Hemoglobin evidence-based interventions and practice (e.g., addressing social factors of health)

Community/System

- Local community demographics

- Culturre, language, and social background

- Leadership and priorities

- Infrastructure and social and individual resources (e.g., childcare, unemployment, housing, transportation)

- Federal, state, and community policies and laws

\section{SUSTAINED IMPACT (3+ YRS)}

- Reduction of

o mother/infant morbidity

o mother/infant mortality

o disparities in mother/infant health

- Improvement of mother, child, and family health

\section{INTERMEDIATE OUTCOMES (2-3 YRS)}

Participant

- Maintenance of healthy habits (e.g., nursing, nutriment)

- Reduction of unplanned pregnancies

- Improvement of birth outcomes

n Preservation of family resilience

Program/Organizational System

- Maintenance of services with enhanced ability to meet social factors of health

- Sustainability of integration and collaboration of care

Community/System (Level 2 and 3 grantees)

a Increment of

o cooperation and integration among and within systems

o coordination of state and local policies for health and social services

\section{Mixed Service Delivery Model of Federal Healthy Start}

Mixed service delivery model is a service delivery model in which local general servers, semi-experts, and experts participate to attempt interdisciplinary approach by constructing cooperative system to provide not only health care service but also diverse social services.

In this model, the service providers visit not only homes but also several places in the community e.g., schools, hospitals, religious facilities, local inhabitant centers, large apartment complex, etc. Providers 
from the same community sharing language, race, socio-economic status and life-experiences participate as members of the service providing group. This activity is found to be quite cost-effective, recruiting service program clients and improving service effect[8]. Further, mixed service delivery model flexibly allow the social service practice to meet the desires of the local inhabitants based on their active participation.

However, this model does not merely provide health care services to pregnant, delivery women, and children, but also child abuse prevention and intervention, parent education, family planning, vocational training, and socio-psychological support services. The core delivery method of mixed service model is home visiting, which is mainly composed of servers, semi-experts, local health activists, and experts in the community. For instance, it is composed of licensed nurses, social workers, psychological counselors, case management experts, etc. Competent local health activists intervene with the vulnerable community to play the role and function of connection ring between the community and the service delivery system.

According to the study results, local health activists got considerable result in maternity health, child immunity and the first and second prevention education, improving service accessibility as cultural arbitrator[9]. This implies that the intervention of providers from community with cultural background who better understand community inhabitants affects trust relation built between service providers and clients. Further, local health activist provides health education, early test, and early discovery service and urgent service. The contribution to the communication between service providers and clients, security of sustainable service, and advocacy of service objects lead to a qualitative improvement of service .

Case management provided through home visiting pays attention to environmental factors which negatively affects service clients. Promptly linking diverse supports to solve clients' problem, enhancing intervention effect, and paying constant attention to clients represents their position, forms mutual reliability, and their life[10]. In this sense, as the indispensable factor of home visiting, the formation of trust relation is said to be the factor to predict efficiency and effect of service.

In summary, mixed service delivery model presents the clear frame of supplying and delivering service by utilizing human and material resource of community in accordance with clients' characteristics and desire through home visiting and case management service in the community.

\section{The Situation of Community Service Delivery System in Korea}

Public delivery system is a dual structure in which basic direction and guideline of policy is fixed by the Ministry of Health and Welfare and executed by local government ('eup', 'myun', 'dong').

Public delivery system has a merit where system and program can be stably maintained in the aspect of finance and supervision. However, public delivery system in bureaucratic character cannot actively and promptly provide diverse and complex service, considering the characteristics of the community and the resident's requirements. For instance, it is difficult to opportunely provide necessary service in situation like early intervention to family in crisis or needing urgent medical support. Further, service is quite likely to be redundant or omitted in the case of welfare service, because service level varies by area and it is separated from health and medical service. Since public delivery system provides categorized service it cannot provide integrated service completely[11].

Further, outreach or home visiting service is impossible due to lack of manpower. As a result, it is difficult to meet residents' requirement preemptively and preventively by searching service targets. Since residents' accessibility to service and relevant information is low, their participation in the development and planning of service is quite limited and the desire of clients cannot be reflected. Considering that the role of public delivery system in service production is below three percent[12], the cooperation with private institution and residents is essential. 
However, community network, which can ensure coordination, connection, and cooperation between them, is quite meager. Thus, it is urgent to introduce a system that will play the role of managing services on public and private delivery systems and guaranteeing residents' participation in the community level. While private delivery system in community is operated mainly by social welfare corporation, foundation and incorporated association, and religious group, it cannot be uniformly classified like public delivery system due to its diverse and complex characteristics.

One of the phenomena arising in relation to local private welfare delivery system in Korea is the disorderly establishment and competition of local welfare service delivery institutions and absence of local welfare cooperative construction system. One of the factors leading to this situation is the privatization of welfare service. Further, even profit-making businesses participate in providing service due to amendment of social welfare business law, aggravating disorderly establishment and competition. Efficient connection of service is difficult and thus service effect is quite limited as local welfare delivery system is fragmentarily operated[13].

Service consumers point out that service is centered on suppliers, not on users, asserting their right of using the service. Community assurance council, which should play the role of adjusting welfare services in community, is formal and nominal.

Thus, the most serious problem of local private welfare service delivery system is that networking, which coordinates and connects diverse service providers in the area, is quite meager. pacifically, integrative service cannot be provided, because operation and connection among service programs is insufficient. For instance, since child abuse and neglect in the community is caused by complex reasons such as psychological, emotional, and socio-economic problem of abusers and victims, service providers in the community intervene to solve problem through cooperative relation with providers in the community. However, the connected service provided by local the child-care institution in cooperation with related public and private service providers is below $0.1 \%[14]$.

\section{Conclusion}

This study intended to investigate the programs and features of the Federal Healthy Start in the USA and to suggest the improvement plan of social welfare services and delivery systems in Korea. For this purpose, various domestics and foreign research papers, books and surveys published by private and public institutions were reviewed. The following implications were drawn.

It is necessary to establish a user-oriented integrative social service delivery system by fully utilizing local resources through cooperation and connection between diverse public and private institutions, which provide service in the community. To this end, mainly the local public institution or social welfare center should coordinate diverse services of service providers, overseeing recruiting service clients, educating and training service providing manpower, the planning and developing service programs.

The local welfare center can support mutually supplementary services through local hospitals, health centers, family consultation centers, child-care centers, and nursing facilities through informationsharing on the availability of resources in the region and the inhabitants' demographic property and desires by constructing a cooperative system with the basic local government. Additionally, unification may be attempted by merging institutions, but administrative management costs may rise, causing several internal issues such as conflict over power, leadership problem, and budget. Thus, coordination and connection among present institutions whose service delivery system are separated seems more appropriate.

It should not be overlooked that the inhabitants' participation should be ensured. Where service design, service type and delivery method are discussed and determined with inhabitants, participation can be promoted and service effect may be also increased because service meeting inhabitants' necessities and desires may be provided[15]. 
Second, home visiting system should be introduced urgently. A Team should be composed mainly of community manpower to provide service, which meets not only home, but also characteristics and desire of community people. Then, the efficiency as well as expertise of service can be enhanced, realizing high cost-effectiveness. Teams may instruct, reinstruct, and train general servers, semi-experts, and experts who can provide service by visiting homes. For instance, family function of vulnerable families in the community can be improved by providing health care service as well as nurture knowledge and technique through home visiting. Further, the benefit of counseling service, vocation service, and recreation service can be also provided through case management service. Home visiting can be said to be the most effective method which increases service accessibility by removing clients' geographic and psychological problems[16].

In addition, case management is also regarded as an effective social service delivery tool to cope with the needs of clients. In the future, case management should be extensively introduced for people that are at-risk for complex issues.

Third, it is required to discuss and determine the design of service, character, kinds of service and its delivery method through local inhabitants' active participation. Then, the empowerment formed by satisfying inhabitants' desire and participation makes it easy to enhance and recover the control of situation that the clients face, thereby leading to community and individual changes[17].

Fourth, similar to the financial support and cooperative relation of federal government and local governments in each level considerably affects the settlement and expansion of Federal Healthy Start in U.S.A., the administrative and financial support is required through close cooperation with the central government in relation to the local service infrastructure amplification and reorganization of the local welfare system, new service providing mode.

Fifth, it is urgent and essential to cooperate between local civil and public sectors, and to improve the ways of financing system in community social welfare settings[18].

To cope with these problems, relevant cooperation model should be developed based on the understanding of Federal Healthy Start. The limitation of this study is that more consideration should be given to social, economic and cultural differences between two countries. Therefore, on the basis of this recognition of the problem, a more detailed comparison and study on possibility of applicability are needed while considering various differences between the two countries in the future.

\section{Acknowledgments}

This article was supported with research funds for sabbatical semester (1st, 2020) of Mokwon University.

\section{References}

[1] J. G. Escarne, H. K. Atrash, D. S. de la Cruz, B. Baker, M. Reyer, Introduction to the Special Issue on Healthy Start, Maternal and Child Health Journal, (2017), Vol.21, Special Issue 1, pp.1-3, https://doi.org/10.1007/s10995-017-2404y

[2] S. R. Parasuraman, D. S. de la Cruz, Evaluation of Implementation of the Healthy Stat Program: Findings from 2016 National Healthy Start Program Survey, Maternal and Child Health Journal, (2019), Vol.23, No.2, pp.220-227, https://doi.org/10.1007/s10995-018-2640-9

[3] B. I. Roh, An Ecological Perspective and the Relationship between Social Capital and Child Development, Journal of Parent Education, (2015), Vol.7, No.1, pp.85-100, UCI : G704-SER000001622.2015.7.1.005

[4] Supporting Statement Revision, http://www.reginfo.gov./HS, Apr 11 (2011)

[5] T. Anderson-Reves, J. Goodmam, B. Bragg, C. Leruth, House Parties: An Innovative Model for Outreach and 
Community-Based Health Education, Maternal and Child Health Journal, (2017), Vol.21, Special Issue 1, pp.75-80, https://doi.org/10.1007/s10995-017-2378-9

[6] I. K. Moise, P. F. Mulhall, Providers' Perspectives on Case Management of a Healthy Start Program: A Qualitative Study, (2016), PLOS ONE, Vol.11, No.6, https://doi.org/10.1371/journal.pone.0157803

[7] http://www. healthystartepic.drg/wp-content, Nov 14 (2015)

[8] L. Roman, J. E. Raffo, Q. Zhu, \& C. I. Meghea, A Statewide Medicaid Enhanced Prenatal Care Program: Impacts on Birth Outcomes, JAMA Pediatrics, (2014), Vol.168, No.3, pp.220-227, doi: 10.1001/jamapediatrics.2013.4347

[9] S. Javanparast, A. Windle, T. Freeman, F. Baum, Community Health Worker Programs to Improve Healthcare Access and Equity: Are They Only Relevant to Low-and Middle-Income Countries?, International Journal of Health Policy and Management, (2018), Vol.7, No.10, pp.943-954, 10.15171/IJHPM.2018.53

[10] Bo Ki Pyon, On the Relationship Between Stress and Bealth of College Students and Mediating Efforts of Social Support, Asia-Pacific Journal of Convergent Research Interchange, (2017), Vol.3, No.4, pp.43-56.

[11] Jae Yoon Lee, Lahari Kolasani, Security Based Network for Health Care System, Asia-Pacific Journal of Convergent Research Interchange, (2015), Vol.1, No.1, pp.1-6, http://dx.doi.org/10.21742/apjcri.2015.03.01

[12] Y. J. Kim, Social Welfare Delivery System in the late 20 Years and Future Prospect, The Conference Materials of the Korean Society of Public Social Welfare Administration, (2019), pp.19-27.

[13] S. J. Choi, K. M. Nam, Social Welfare Administration, Na Nam, ISBN 9788930088596, pp.612, (2016)

[14] Child Abuse and Neglect Korea 2014, Central Institute for Child Protection, (2014)

[15] G. Y. Yang, Social Service and Publicness in Local Community, Korean Public Management Review, (2013), Vol.27, No.1, pp.89-114, DOI : 10.24210/kapm.2013.27.1.004

[16] H. Y. Kim, Community-based Organization and Social Services, The Workshop Materials of the Korean Society of Social Welfare Administration, (2012), pp.81-104.

[17] Eun Mee Choi, The Married Migrant Women's Adaptation to Korean Society, Asia-Pacific Journal of Convergent Research Interchange, (2018), Vol.4, No.2, pp.31-42, DOI : 10.14257/apjcri.2018.06.04

[18] C. Y. Nam, R.Y. Jeon, A Suggestion for Improvement of the Social Welfare Delivery System of Local Communitycentered, Journal of Community Welfare, (2012), No.43, pp.513-530. 